\title{
PEDIATRIC HERNIOTOMY: A 2-YEAR FOLLOW-UP STUDY AT NEPAL MEDICAL COLLEGE AND TEACHING HOSPITAL
}

\author{
Pradhan GBN, Shrestha S, Chalise A, Shrestha S
}

Department of Surgery, Nepal Medical College Teaching Hospital, Attarkhel, Gokarneshwor-8, Kathmandu, Nepal

\begin{abstract}
Repair of inguinal hernia is one of the most commonly performed pediatric surgical procedures. The standard of treatment has been open herniotomy $(\mathrm{OH})$. Recent trends have shown promising results with use of laparoscopy (LH) for the same. The aim of this study was to compare laparoscopic herniotomy with the standard of care at the time of the study, which has become an increasingly common procedure at our center. This was a prospective follow-up study conducted at the Department of Surgery at Nepal Medical College and Teaching Hospital. A total of sixtyfour patients who underwent herniotomy were included in the study and followed up for a total duration of two years post-operatively. Immediate post-op pain was assessed with the use of visual analogue scales. Complications, recurrence, and metachronous herniation were noted in the follow up visits. Use of laparoscopy resulted in a longer operative time (36.68 min vs 22.5 min for $\mathrm{OH}, \mathrm{P}<0.001$ ). Pain scores were similar at immediate post-op period (LH 4.18 vs OH 3.93) but decreased significantly for LH compared to $\mathrm{OH}$ at 6 hours (3.68 vs $4.31, \mathrm{P}=0.018$ ), 12 hours ( 2.71 vs $3.62, \mathrm{P}<0.001$ ), and 24 hours ( 2 vs 3.03 , $\mathrm{P}<0.001$ ). Difference in the mean hospital stay was statistically significant (LH 2.02 days vs OH 2.34 days, $\mathrm{P}<0.001$ ). No recurrences occurred during the follow up period of the study. No patients developed contralateral metachronous hernia during the follow-up period. The cost of $\mathrm{OH}$ compared to $\mathrm{LH}$ was significantly less. $\mathrm{LH}$ is a safer and better alternative to $\mathrm{OH}$ for management of pediatric inguinal hernia when comparing post-op pain and hospital stay. However, duration of surgery and cost for the procedure favor $\mathrm{OH}$ at present in our setup.
\end{abstract}

\section{KEYWORDS}

Herniotomy, inguinal hernia, laparoscopy, pediatrics, pediatric surgery

\section{CORRESPONDING AUTHOR}

Dr. Giridhar Bahadur Nhuchhe Pradhan,

Associate Professor,

Department of Surgery,

Nepal Medical College Teaching Hospital,

Attarkhel, Gokarneshwor-8, Kathmandu, Nepal

Email: gbnpradhan@gmail.com

Orcid No: https://orcid.org/0000-0003-3183-1555

DOI: https://www.doi.org/10.3126/nmcj.v23i1.36229 


\section{INTRODUCTION}

Hernia is a frequently encountered clinical problem. ${ }^{1}$ The incidence in children ranges from 0.8 to $4.4 \%$, which translates roughly to 10 to 20 cases per 1000 live births. ${ }^{2}$ Most congenital hernia cases occur in the male child in their first year of life, decreasing in incidence after 6 months of age. ${ }^{3}$ Hernia in children most frequently occurs in the right side but may be bilateral in approximately $10 \%$ of the time. ${ }^{4}$ All on all, inguinal hernias do not resolve spontaneously so require surgical closure, with most surgeries being performed soon after diagnosis, or after the child has attained a weight of $2 \mathrm{kgs}$ in case of premature birth. ${ }^{5}$

Regardless of the technique used, the principle in pediatric inguinal hernia repair is high ligation of the sac..$^{6,7}$ In either approach for surgery, young children usually undergo hernia repair under general anesthesia. ${ }^{1}$ Many papers have shown that laparoscopic surgery for repair of hernia in children is safe and feasible. ${ }^{8-28}$ These studies have also shown that surgeons seem to prefer extracorporeal suturing and knotting in children, which effectively minimizes the need of multiple endoscopic ports and instruments. In our center hernia repair is performed laparoscopically with the use of only two ports.

The aim of this article is to assess feasibility of laparoscopic hernia repair in a country where laparoscopic surgery is still taking its initial steps, and where this service may not be widely available yet for pediatric age group.

\section{MATERIALS AND METHODS}

Patients under 16 years of age, presenting to the Pediatric Surgery out-patient clinic at Nepal Medical College Teaching Hospital, Attarkhel, Gokarneshwor-8, Nepal, from February 2016 to February 2018, were included in the study if they had both clinical and radiological diagnosis of inguinal hernia. Any patient less than 16 years of age presenting with recurrent hernia, previous abdominal surgery, incarcerated or strangulated hernia, undergoing emergency surgery or when parents refused consent were excluded from the study. The study design was a prospective cohort study (follow-up). A total of 70 patients who presented to the outpatient clinic were approached during the period of the study, who met the inclusion criteria, of which 64 patients consented for inclusion. The patients were given the options of open and laparoscopic surgery, and 32 patients underwent open surgery, while the remaining 32 chose to undergo laparoscopic surgery. Ethical clearance was obtained from the Institutional Review Committee of Nepal Medical College, and consent for procedure was obtained from the parents of the patients undergoing surgery. Follow up was continued till November 2020. Initial follow up visits were conducted at 3 months, 6 months and 1-year post-op. The last follow up was done via phone at a 2-year duration.

\section{Standard Protocol for Herniotomy at Nepal Medical College}

All patients underwent the procedure under general anesthesia with intravenous injection of propofol $3 \mathrm{mg} / \mathrm{kg}$ as induction and isoflurane with $33 \%$ oxygen for maintenance. Intraoperative analgesia was provided with injectable fentanyl at $0.5 \mu \mathrm{g} / \mathrm{kg}$. Surgical technique was standardized for all patients. At the conclusion of the procedure $0.5 \%$ plain bupivacaine $0.1 \mathrm{~mL} / \mathrm{kg}$ was infiltrated in each skin wound site. Post-operatively, the patients were managed for 4 hours in the recovery room, then transferred to the ward. The Children and Infants Postoperative Pain Score (CHIPPS) was used to record the pain level in infants and children 3 years or older at 0, 6, 12 and 24 hours after surgery. ${ }^{29}$ For children more than 3 years of age, Children's Hospital of Eastern Ontario Pain Score (CHEOPS) was used. ${ }^{30}$ CHIPPS $\geq 4$ or CHEOPS $\geq 5$, when recorded, prompted injection of acetaminophen $15 \mathrm{mg} / \mathrm{kg} /$ dose orally for postop pain management, with max dose of $90 \mathrm{mg} /$ $\mathrm{kg} /$ day. Diet was reinstituted once the patients tolerated feed, and they were discharged once stable and feeding well. Post discharge, the patients were followed up after one week, then after 3 months. Further follow-up was done at 6 months, one year and two years post-surgery, till February 2020. The patients were contacted via phone to request for patient status in between follow up visits.

\section{Data Analysis}

Data was entered into Microsoft Excel and analyzed using IBM SPSS ver. 16. Continuous data has been expressed as mean \pm SD. Statistical significance was calculated with a two-tailed independent $t$-test, and chi-square test was used for proportion data. P value $<0.05$ was considered significant.

\section{RESULTS}

The characteristics of the patients were not significant statistically, as shown in Table 1. An interim analysis of the data was conducted, which showed a shorter duration of surgery for the open group (22.9 \pm 5.9 minutes), compared 
to the laparoscopic group (36.68 \pm 5.6 minutes), which was statistically significant for unilateral hernia surgeries. However, the average time for performing open herniotomy for bilateral inguinal hernia was 40 minutes, while the time for laparoscopic surgery for the same was 44.5 minutes, which was not statistically significant $(\mathrm{P}=0.85)$. When compared to a meta-analysis published in 2011 by Alzahem $\mathrm{A},{ }^{31}$ which analyzed data on 2699 children from 10 studies, laparoscopic techniques resulted in higher recurrence rate $(\mathrm{OR}=1.81 ; 95 \% \mathrm{CI}$ 0.89-3.67; $\mathrm{P}=0.10$ ), longer operative time for unilateral repairs, and shorter operative time for bilateral repairs. This was supported by the study by Koivusalo et al. in 2009, which also demonstrated that laparoscopic surgery was associated with a longer operating time (33 min versus 15 min for open surgery; $\mathrm{P}$ < 0.001). ${ }^{28}$ In contrast, Feng et al. published a systematic review of 5 randomized trials with a sample size of 553, showing no significant difference in operative time for unilateral hernia with either technique. ${ }^{24}$ To contradict further, Esposito et al., in another systematic review of 53 studies with 19022 children and adolescents who underwent hernia surgery, showed that there was no significant difference in terms of operative time between $\mathrm{LH}$ and $\mathrm{OH}$ for unilateral repairs (25.9 versus 25.8 minutes) and for bilateral repairs (25 versus 29.8 minutes). ${ }^{12}$ However, our study does show that the operative time is not significant only for bilateral cases at our institute.
Only 2 out of 64 participants developed complications, both from the open herniotomy group. One participant developed seroma, and one developed superficial surgical site infection. The hospital stay was $2.34 \pm 0.48$ days for the open herniotomy group, while it was only 2.03 \pm 0.17 days for the laparoscopic group. This was statistically significant $(\mathrm{P}<0.001)$.

The comparison of pain scores following surgery have been shown in Table 2. It was noted that the laparoscopic group had significantly less pain compared to open group at 6 hours, 12 hours and 24 hours post procedure.

\section{DISCUSSION}

The meta-analysis by Alzhaem A et al, also showed that there was a significant reduction in development of contralateral metachronous inguinal hernia (MCIH) in the laparoscopic group. ${ }^{31}$ Other studies have published data that suggest that $\mathrm{MCIH}$ develops in patients younger than six months old at the time of the surgery $(8.85 \%$ versus $7.12 \%$ in those more than six months at time of surgery; $\mathrm{P}=0.036$ ), and in patients who initially present with a left-sided hernia (9.6\% versus $5.42 \%$ for right sided presentation; $\mathrm{P}<0.001)^{32,33}$ However, there were no recurrences or development of metachronous inguinal hernia in either group in our study, even at a 6-month follow up. On further follow up till 2 years post-op, the patients have not yet developed recurrence or metachronous hernia in either study group.

\begin{tabular}{|lccc|}
\multicolumn{4}{c}{ Table 1: Characteristics of Patients in the study } \\
\hline Open $(\mathbf{n}=\mathbf{3 2})$ & Laparoscopic $(\mathbf{n}=\mathbf{3 2})$ & P value \\
\hline Age (years) & $6.59 \pm 1.34$ & $5.21 \pm 1.46$ & 0.12 \\
Sex & & & \\
Male & 25 & 25 & 1 \\
Female & 7 & 7 & \\
Diagnosis & & & \\
Right & 21 & 25 & 0.309 \\
Left & 10 & 5 & \\
Bilateral & 1 & 2 & \\
\hline
\end{tabular}

\begin{tabular}{|lccc|}
\multicolumn{4}{c}{ Table 2: Pain scores at different intervals in the study } \\
\hline & Open $(\mathbf{n}=\mathbf{3 2})$ & Laparoscopic $(\mathbf{n}=\mathbf{3 2})$ & P value \\
\hline 0 hour & 4.18 & 3.93 & 0.211 \\
6 hours & 4.31 & 3.68 & 0.018 \\
12 hours & 3.62 & 2.71 & $<0.01$ \\
24 hours & 3.03 & 2 & $<0.01$ \\
\hline
\end{tabular}


The cost of open herniotomy at the time of the study was NRs. 10,000 for unilateral cases, and NRs. 15,000 for bilateral cases, whereas the cost of laparoscopic surgery was NRs. 14,000 for unilateral cases, and NRs. 18,000 for bilateral cases. The patients undergoing open surgery at our center had expenditure of NRs. $13,191.25 \pm 883.88$, whereas those undergoing laparoscopic surgery had expenditure of NRs. $17,285 \pm 983.74$. The patients who underwent laparoscopic surgery had to pay a statistically significant amount of money compared to those who underwent open surgery $(\mathrm{P}<0.001)$.

In conclusion, open herniotomy has been the standard procedure for pediatric inguinal hernia repair with a high success rate and low complication rate. Laparoscopic surgery has been taking place of open approaches due to similar operating time, similar complication rates and shorter duration of hospital stay. From our study we can conclude that laparoscopic surgery for hernia repair is a safe alternative to open herniotomy with respect to shorter hospital stay (statistically significant, but may not be clinically significant at present), and lesser post-operative pain and complications. The only short comings for this approach would be a longer operating time, which can be attributed to the longer learning curve for the surgeon, and the cost incurred for the patient, which may lead to patients choosing open herniotomy in favor of laparoscopic herniotomy. However, once sufficient skills have been acquired for laparoscopic herniotomy, one can choose either approach as both seem to be equivocal in achieving the desired outcome for unilateral hernias. For bilateral hernias, we feel that laparoscopic technique is preferable due to similar operating times, less post-op pain and shorter duration of stay as both procedures usually necessitate the use of general anesthesia for the pediatric population undergoing surgery.

\section{ACKNOWLEDGEMENT}

The authors would like to thank Dr. Ritesh Shrestha (Assistant Professor, Department of Surgery) for his invaluable support by performing/assisting in the procedures.

\section{REFERENCES}

1. IPEG Guidelines for Inguinal Hernia and Hydrocele. J Laparoendosc Adv Surg 2010; 20: xii-vi.

2. Coran A, Adzick N, Krummel T, Laberge J, Caldamone A, Shamberger R. Pediatric surgery. Vols 1 \& 2. 7th ed. Philadelphia: Elsevier Saunders; 2012.

3. Esposito C, Turial S, Escolino Met al. Laparoscopic inguinal hernia repair in premature babies weighing $3 \mathrm{~kg}$ or less. Pediatr Surg Int'l 2012; 28: 989-92.

4. Hutson J, O’Brien M, Woodward A. Jones' Clinical Paediatric Surgery. 6th ed. Chichester: John Wiley \& Sons; 2009.

5. Zavras N, Christou A, Misiakos E et al. Current Trends in the Management of Inguinal Hernia in Children. Int'l J Clin Med 2014; 05: 770-7.

6. Pediatric Laparoscopic Inguinal Hernia Repair: A Review of Techniques. SAGES. 2020.

7. Lukong C. Surgical techniques of laparoscopic inguinal hernia repair in childhood: A critical appraisal. J Surg Tech Case Report 2012; 4: 1.

8. Zani A, Eaton S, Hoellwarth M et al. Management of Pediatric Inguinal Hernias in the Era of Laparoscopy: Results of an International Survey. Eur J Pediatr Surg 2013; 24: 9-13.

9. Brandt M. Pediatric Hernias. Surg Clin North Am 2008; 88: 27-43.

10. Miltenburg D, Nuchtern J, Jaksic T, Kozinetiz
C, Brandt M. Laparoscopic evaluation of the pediatric inguinal hernia-A meta-analysis. $J$ Pediatr Surg 1998; 33: 874-9.

11. Nasir A, Abdur-Rahman L, Kedari $\mathrm{P}$ et al. Laparoscopic inguinal hernia repair in children: A single-centre experience over 7 years. Afr $J$ Paediatr Surg 2012; 9: 137.

12. Esposito C, St. Peter S, Escolino M, Juang D, Settimi A, Holcomb G. Laparoscopic Versus Open Inguinal Hernia Repair in Pediatric Patients: A Systematic Review. J Laparoendosc Adv Surg 2014; 24: 811-8.

13. Becmeur F, Philippe P, Lemandat-Schultz A et al. A continuous series of 96 laparoscopic inguinal hernia repairs in children by a new technique. Surg Endosc 2004; 18: 1738-41.

14. Schier F. Laparoscopic surgery of inguinal hernias in children-Initial experience. J Pediatr Surg 2000; 35: 1331-5.

15. Schier F. Laparoscopic inguinal hernia repair-a prospective personal series of 542 children. J Pediatr Surg 2006; 41: 1081-4.

16. Lee Y, Liang J. Experience with 450 Cases of Micro-Laparoscopic Herniotomy in Infants and Children. Pediatr Endosurg Innovative Tech 2002; 6: 25-8.

17. Hassan M, Mustafawi A. Laparoscopic Flip-Flap Technique Versus Conventional Inguinal Hernia Repair in Children. JSLS 2007; 11: 90-3. 
18. Tsai Y, Wu C, Yang S. Minilaparoscopic herniorrhaphy with hernia sac transection in children and young adults: a preliminary report. Surg Endosc 2007; 21: 1623-5.

19. Yildiz A, Çelebi S, Akin M et al. Laparoscopic hernioraphy: a better approach for recurrent hernia in boys?. Pediatr Surg Int'l 2012; 28: 44953.

20. Kokorowski P, Wang H, Routh J, Hubert K, Nelson C. Evaluation of the contralateral inguinal ring in clinically unilateral inguinal hernia: a systematic review and meta-analysis. Hernia 2013; 18: 311-24.

21. Ponsky T, Nalugo M, Ostlie D. Pediatric Laparoscopic Inguinal Hernia Repair: A Review of the Current Evidence. J Laparoendosc Adv Surg 2014; 24: 183-7.

22. Lee K, Yeung C. Laparoscopic Surgery in Newborns and Infants: An Update. HKJ Paediatr (New Series) 2003; 8: 327-35.

23. Davenport M. Laparoscopic surgery in children. Ann R Coll Surg Engl 2003; 85: 324-30.

24. Feng S, Zhao L, Liao Z, Chen X. Open Versus Laparoscopic Inguinal Herniotomy in Children. Surg Laparosc Endosc Percutan Tech 2015; 25: 275-80.

25. Yang C, Zhang H, Pu J, Mei H, Zheng L, Tong Q. Laparoscopic vs open herniorrhaphy in the management of pediatric inguinal hernia: a systemic review and meta-analysis. J Pediatr Surg 2011; 46: 1824-34.

26. Chan K, Hui W, Tam P. Prospective randomized single-center, single-blind Comparison of laparoscopic vs open repair of pediatric inguinal hernia. Surg Endosc 2005; 19: 927-32.

27. Shalaby $\mathrm{R}$, Ibrahem $\mathrm{R}$, Shahin $\mathrm{M}$ et al. Laparoscopic Hernia Repair versus Open Herniotomy in Children: A Controlled Randomized Study. Minim Invasive Surg 2012; 1-8.

28. Koivusalo A, Korpela R, Wirtavuori K, Piiparinen S, Rintala R, Pakarinen M. A Single-Blinded, Randomized Comparison of Laparoscopic Versus Open Hernia Repair in Children. Pediatr 2009; 123: 332-7.

29. Büttner W, Finke W. Analysis of behavioural and physiological parameters for the assessment of postoperative analgesic demand in newborns, infants and young children: a comprehensive report on seven consecutive studies. Pediatr Anesth 2000; 10: 303-18.

30. Suraseranivongse S, Santawat U, Kraiprasit K, Petcharatana S, Prakkamodom S, Muntraporn N. Cross-validation of a composite pain scale for preschool children within 24 hours of surgery. Br J Anaesth 2001; 87: 400-5.

31. Alzahem A. Laparoscopic versus open inguinal herniotomy in infants and children: a metaanalysis. Pediatr Surg Int'l 2011; 27: 605-12.

32. Ron O, Eaton S, Pierro A. Systematic review of the risk of developing a metachronous contralateral inguinal hernia in children. $B r$ J Surg 2007; 94: 804-11.

33. Nataraja R, Mahomed A. Metachronous contralateral pediatric inguinal hernia. Open Access Surg 2010; 3: 87-90. 